\title{
Activation of the $h T E R T$ expression in squamous cell cervical carcinoma is not associated with gene amplification
}

\author{
EKATERINA ANEDCHENKO ${ }^{1}$, NINA OPARINA ${ }^{1}$, ALEXEI DMITRIEV ${ }^{1}$, GEORGE KRASNOV ${ }^{1}$, \\ LARISA PAVLOVA $^{2}$, NATALYA ALEXANDROVA ${ }^{2}$, FJODOR KISSELJOV ${ }^{2}$ and VERA SENCHENKO ${ }^{1}$ \\ ${ }^{1}$ Engelhardt Institute of Molecular Biology, Russian Academy of Sciences, 119991 Moscow; \\ ${ }^{2}$ Blokhin Cancer Research Center, Russian Academy of Medical Sciences, 115478 Moscow, Russia
}

Received March 4, 2008; Accepted April 21, 2008

DOI: $10.3892 /$ or_00000030

\begin{abstract}
The hTERT gene encodes the telomerase catalytic subunit that plays a key role in cancer cell immortalization. Earlier, hTERT amplification was detected in squamous cell cervical carcinomas (SCC), however possible relations between elevated $h T E R T$ mRNA level and gene amplification was not studied. Here, we compared the hTERT expression and copy number in the same tumors by quantitative real-time PCR. The hTERT DNA copy number was virtually unchanged in all 33 studied tumors, when compared to normal tissues. This result was confirmed using two reference genes $B$-actin and B-D-glucuronidase. Nevertheless, the activation of $h T E R T$ expression was found in $80 \%$ of cases $(37 / 46, \mathrm{p}<0.001)$. There was no correlation between the degree of mRNA increase and the tumor size and/or presence of metastases. No hTERT gene expression was observed in $20 \%$ of cases (9/46), while the control GADPH expression was unchanged. The detected elevation of the hTERT mRNA level was found using primers specific to functionally active full-length isoform of mRNA. Similar results were obtained with SCC cell lines carrying human papilloma virus (HPV) genomes. We conclude that frequent activation of hTERT expression in SCC is not associated with gene amplification.
\end{abstract}

Correspondence to: Dr Vera Senchenko, Laboratory of Structural and Functional Genomics, Engelhardt Institute of Molecular Biology, Russian Academy of Sciences, Moscow, Vavilov Str. 32, 119991 Russia

E-mail: versen@eimb.ru

Abbreviations: ACTB, beta-actin; GAPDH, glyceraldehyde-3phosphate dehydrogenase; GUSB, beta-D-glucuronidase; HPV, human papilloma virus; $h T E R T$, gene coding catalytic subunit of telomerase; SCC, squamous cell cervical carcinomas; qPCR, quantitative real-time PCR

Key words: telomerase, hTERT mRNA level, hTERT DNA copy number, squamous cell cervical carcinoma, quantitative real-time PCR

\section{Introduction}

Telomerase plays a key role in controlling cell proliferation activity. This enzyme was detected in most immortalized tumor cells and stem mammalian cells (1). Telomerase is a ribonucleoprotein complex, composed of an RNA component (hTR), catalytic subunit (hTERT) that exhibits the reverse transcriptase activity, and a number of accessory proteins. Telomerase catalyses telomere elongation and maintains the proper telomere size. The hTR is constitutively expressed in all cells (2) in contrast to the hTERT that is not expressed in differentiated cells.

The hTERT gene is localized on chromosome $5 \mathrm{p} 15.33$ and composed of 16 exons. Only full-length isoform of hTERT mRNA encodes a catalytically active telomerase. Mechanisms controlling the level of this mRNA isoform probably include transcriptional regulation (e.g. promoter demethylation, (in)activation due to transcription factors binding), alternative splicing and gene amplification. The hTERT gene promoter contains binding sites for repressors (p53, Mad1, etc.) and activators of expression (c-Myc, Sp1) (3). The hTERT gene amplification was found in different primary tumors and cell lines. In squamous cell cervical carcinomas (SCC), an increase in hTERT copy number was found in $24 \%$ of cases. It correlated significantly with higher levels of $h T E R T$ protein expression $(4,5)$.

SCC is characterized by well defined clinical stages (from several forms of intraepithelial dysplasia to invasive carcinomas); and by the presence of integrated or episomal forms of human papilloma virus (HPV) DNA from so-called high risk group (HPV types 16, 18 and related). Recent qPCR studies showed that $h T E R T$ mRNA level increased even in precancerous lesions (6). However, the role of hTERT activation at early stages of SCC remains unclear. Gene amplification was discussed as one of the possible mechanisms of hTERT activation $(4,5)$. Here we quantitatively measured hTERT gene copy number and mRNA level in the same SCC specimens and found that elevation of hTERT mRNA level is not associated with gene amplification.

\section{Materials and methods}

Specimens. SCC and adjacent morphologically normal tissues were obtained from patients after surgery in accordance 
with the rules issued by the Ethics Committee of Blokhin Cancer Research Center, Moscow, Russia. The samples were immediately frozen and stored in liquid nitrogen. All tumors were classified histopathologically and characterized according to the International System of Clinico-Morphological Classification of Tumors (TNM). The HPV genome from the 'high-risk' group (types 16 and/or 18) was present in all carcinomas as described earlier (7).

Cell culture. Five SCC cell cultures were obtained from American Type Culture Collection: four HPV-containing lines (HeLa with multiple copies of HPV18 and CaSki, SiHa, and C4-1 cells with different copy numbers of HPV16) and one HPV-free line (C33a).

DNA and RNA extraction. Total DNAs and RNAs were extracted and isolated as described earlier (8). DNAs and RNAs were analysed by electrophoresis in $2 \%$ agarose and quantified using spectrophotometer (Nanodrop Technologies Inc).

DNA samples from 33 SCC tissues and 17 samples of adjacent morphologically normal tissues were analyzed. Fortysix mRNA samples from SCC tissues and 20 samples from adjacent morphologically normal tissue were also studied. All RNA samples were treated with DNase I and cDNA was synthesized using MMLV reverse transcriptase and random hexamers according to standard manufacturer's protocol (Fermentas, Lithuania). Thirty-three DNA and mRNA samples were obtained from the same SCC tissues.

Primer design. The primers and probes were designed using the Primer Design program (EIMB RAS, Russia, www. imb.ac.ru/ nixie/PD/PD.rar).

Set 1: Primers specific to exon 2 of hTERT mRNA and common for genomic hTERT DNA and all known mRNA isoforms (genomic positions 1606-1623, forward, and 17111729, reverse). Forward, reverse primers and probe were as follows: 5'-AACGAACGCCGCTTCCTC-3'; 5'-GCTCC TGCGCAGCCAAG-3'; 5'-CAGTCCCGCACGCTCATCTT CCACGT-3', the amplicon length is $142 \mathrm{bp}$.

Set 2: Primers specific to full-length hTERT isoform 1 only. Forward primer crossed the boundary of exon 5 and exon 6 (genomic region 2174-2198). Reverse primer was specific to isoform 1 and 2, it was located in exon 7 (genomic region 2353-2374). Forward, reverse primers and probe for hTERT gene were as follows: 5'-CTGTACTTTGTCAAGGT GGATGTGA-3' 5'-GTACGGCTGGAGGTCTGTCAAG-3'; 5'-CAGGCTCACGGAGGTCATCGCC-3', the amplicon length is $198 \mathrm{bp}$. Forward, reverse primers and probe for the reference gene ACTB (\#NM_001101.2): 5'-GTGCTCA GGGCTTCTTGTCCTTT-3', 5'-TTTCTCCATGTCGT CCCAGTTGGT-3', 5'-AGGATTCCTATGTGGGCGA CGAGGCCCA-3', the amplicon length is 160 bp. Forward, reverse primers and probe for the reference gene $G U S B$ (\#NM_000181): 5'-TGCCGTGAGTCTCTGCTGTG-3', 5'-CCTACGCACCACTTCTTCCATC-3', 5'-TGACCCTC TGTCCCTTCCCTCCTG-3', the amplicon length is $152 \mathrm{bp}$. Forward, reverse primers and probes for the GAPDH (\# NM_002046): 5'-CGGAGTAACGGATTTGGTC-3', 5'-TG GGTGGAATCATATTGGAACAT-3', 5'-CCCTTCATT GACCTCAACTACATGGTTTACAT-3', the amplicon length is $141 \mathrm{bp}$. All probes were labeled with a reporter dye (6-carboxy-florescein, FAM) at their 5'-end and a dark quencher dye RTQ1 (Sintol, Russia) at their 3'-end.

Quantification of hTERT mRNA level in SCC. TaqMan qPCR was carried out with Sequence Detection System ABI 7000 PRISM $^{\text {TM }}$ SDS (Applied Biosystems). For qPCR mixtures the following final compositions were used: $12.5 \mu 1$ standard 1X qPCR buffer Reality (EIMB RAS, Moscow) (9), the analogue of TaqMan Universal PCR Master Mix (Applied Biosystems), primers and probes in optimal concentrations and $2 \mu \mathrm{l}$ template in total volume of $25 \mu \mathrm{l}$ in triplicate. Final concentrations were as follows: hTERT primers - $300 \mathrm{nM}$, probe - $300 \mathrm{nM}$ (set 1) and primers - $300 \mathrm{nM}$, probe - $400 \mathrm{nM}$ (set 2); GAPDH primers - $300 \mathrm{nM}$, probe - $150 \mathrm{nM}$. The thermocycler conditions were $10 \mathrm{~min}$ at $95^{\circ} \mathrm{C}$, then 50 twostep cycles $15 \mathrm{sec}$ at $95^{\circ} \mathrm{C}$ and $60 \mathrm{sec}$ at $60^{\circ} \mathrm{C}$. The sequences of the amplicons were verified by sequencing in a 3730 DNA Analyzer automated sequencer (Applied Biosystems). qPCR data were analyzed using the relative quantification (http:// docs.appliedbiosystems.com/pebiodocs/04303859.pdf) based on mRNA levels ratio of $h T E R T$ gene normalized to a reference gene $G A P D H$ in a given tumor sample relative to another reference sample. All necessary control experiments were done. We performed standardization of all assays, selection of reference samples, evaluation of reference genes variability and efficiency of PCR reactions (http//www.genequantification.info/). As a reference samples we used two tumor cDNA samples with minimal hTERT expression instead of normal cDNAs where no hTERT transcripts were detected. The variability of GAPDH mRNA level was no higher than 2-fold in tumor (T) and normal $(\mathrm{N})$ tissues. The raw data were analyzed using the program AEGIS (analysis of expression of genes in paired samples, the registration number 2006613816, 2006, Rospatent, Russia). The reaction efficiencies (E) calculated using the AEGIS and relative standard curves $(*)$ were similar: $\mathrm{E}=(80 \pm 7) \%,{ }^{*} \mathrm{E}=(75 \pm 7) \%$ for $h$ TERT in tumors; $\mathrm{E}=(89 \pm 8) \%,{ }^{*} \mathrm{E}=(92 \pm 9) \%$ for $G A P D H$ in $\mathrm{T}$ and $\mathrm{N}$. All analyzed tumors expressed n-fold amount of $h T E R T$ mRNA relative to the reference samples. For 3 amplification curves only semiquantitative analysis was performed because of low E values for hTERT in SCC samples.

Quantification of hTERT DNA copy number in SCC. Final concentrations were for $h T E R T$ primers - $300 \mathrm{nM}$, probe $300 \mathrm{nM}$; $A C T B$ primers - $200 \mathrm{nM}$, probe - $100 \mathrm{nM}$; GUSB primers - $200 \mathrm{nM}$, probe - $200 \mathrm{nM}$. Other conditions were the same as for mRNA quantification. As a reference we used paired normal samples or their pools. All analyzed tumors expressed n-fold copy number of hTERT DNA relative to the reference samples. Values $\mathrm{E}$ in normal and tumor samples were close to each other: $(92 \pm 8) \%$ for hTERT; $(82 \pm 6) \%$ for $A C T B$ and $(86 \pm 4) \%$ for GUSB. The variability of $A C T B$ and $G U S B$ copy number was no higher than 1.6-fold in tumor (T) and normal $(\mathrm{N})$ tissues.

Statistical analysis. We compared mRNA level and DNA copy number differences of target and reference genes for the same cervical cancer patients using a non-parametric Wilcoxon test. The evaluation of statistical significance of 




Figure 1. Schematical map of the $h T E R T$ and mRNA isoforms. Primer positions are designated by arrowheads. Structure of the $h T E R T$ full-length isoform 1 and non-functional isoforms 2 and 4 is also shown.

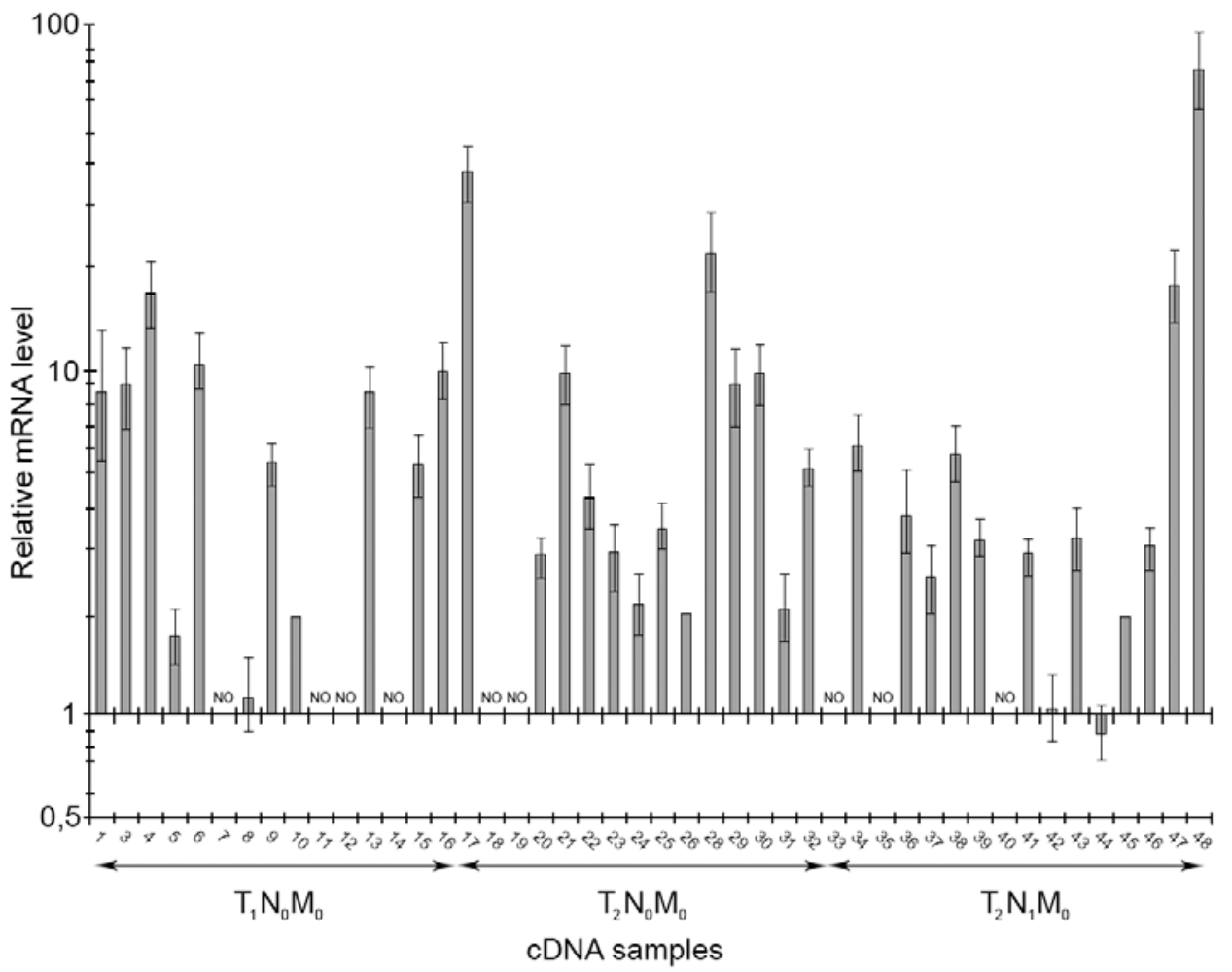

Figure 2. The level of $h T E R T$ mRNA in primary SCC relative to the reference gene GAPDH.

mRNA level was tested for all studied cases and for paired groups with different clinical characreristics. P-values $<0.05$ were considered statistically significant. The statistical analysis was performed using the BioStat software 'Practice' (2006) as previously described (10).

\section{Results}

Three variants of $h T E R T$ gene transcripts were known: the full-size isoform 1 (Genbank \#NM_198253); isoform 2 encoding a non-active protein (\#NM_198255), and truncated isoform 4 that does not encode any protein (\#NM_198254). Isoform 1 differs from isoforms 2 and 4 by localization of exon-exon borders. In order to quantify $h T E R T$ mRNA in SCC we designed two primer sets (set 1 and set 2) that distinguish the full-length isoform 1, isoform 2 and isoform 4 (Fig. 1). We used qPCR for hTERT mRNA level and gene copy number analysis in SCC and adjacent normal cervical tissues. To examine $h T E R T$ expression we applied primer set 2 . In $80 \%(37 / 46, \mathrm{p}<0.001)$ of SCC $h T E R T$ gene expression was 
Table I. The hTERT mRNA level and hTERT copy number in SCC.

\begin{tabular}{lcc}
\hline & \multicolumn{2}{c}{ Frequency increase $\%$} \\
\cline { 2 - 3 } $\mathrm{TNM}$ & mRNA level & DNA copy number \\
\cline { 2 - 3 } classification & Increase & Retention \\
\hline $\mathrm{T}_{1} \mathrm{~N}_{0} \mathrm{M}_{0}$ & $75(12 / 16)$ & $100(15 / 15)$ \\
& $\mathrm{p}<0.02$ & $\mathrm{p}<0.01$ \\
$\mathrm{~T}_{2} \mathrm{~N}_{0} \mathrm{M}_{0}$ & $81(13 / 16)$ & $100(11 / 11)$ \\
& $\mathrm{p}<0.02$ & $\mathrm{p}<0.01$ \\
$\mathrm{~T}_{1} \mathrm{~N}_{0} \mathrm{M}_{0}+\mathrm{T}_{2} \mathrm{~N}_{0} \mathrm{M}_{0}$ & $78(25 / 32)$ & $100(26 / 26)$ \\
without metastases & $\mathrm{p}<0.001$ & $\mathrm{p}<0.01$ \\
$\mathrm{~T}_{2} \mathrm{~N}_{1} \mathrm{M}_{0}$ & $86(12 / 14)$ & $100(7 / 7)$ \\
with metastases & $\mathrm{p}<0.02$ & $\mathrm{p}<0.01$ \\
Total & $\mathbf{8 0}(37 / 46)$ & $\mathbf{1 0 0}(33 / 33)$ \\
& $\mathrm{p}<0.001$ & $\mathrm{p}<0.01$ \\
\hline
\end{tabular}

activated in tumor tissues (Fig. 2). The range of activation was between 2 - and 80 -fold. In $35 \%$ (16/46) of cases expression increased from 2- to 10-fold, and in 24\% (11/46) of cases $>10$-fold increase was observed. Maximal increase was 80-fold (range 72-95) for a single specimen No $46\left(\mathrm{~T}_{2} \mathrm{~N}_{1} \mathrm{M}_{0}\right)$. The frequency and the extent of the increase of hTERT mRNA was independent of tumor size $\left(\mathrm{T}_{1}-\mathrm{T}_{2}\right)$ and of the presence of metastases in regional lymph nodes $\left(\mathrm{N}_{1}\right)$ (Fig. 2, Table I). In $20 \%(9 / 46)$ of cases expression of hTERT was below detectable level.

To define if the detected hTERT overexpression in SCC was linked to functionally active full-lenghth isoform 1 of telomerase, we compared the results of mRNA quantification using primer sets 1 and 2 only for 21 RNA samples because of limited quantity of template. For 91\% (19/21) of tested samples the data were similar for both sets (Table II). Thus, hTERT mRNA was synthesized as a full-length isoform 1 .

In order to answer the question, whether the increase of hTERT mRNA level resulted from gene amplification, we performed quantitative evaluation of hTERT gene copy number using primer set 1 (Fig. 3, Table I). The results were normalized vs. two reference genes. The average hTERT DNA copy number was equal to $1.1 \pm 0.2$ for both $A C T B$ and GUSB genes. Finally, copy number of the hTERT was virtually unchanged in all 33 tumor samples compared to adjacent normal tissues, independently of the tumor size $\left(\mathrm{T}_{1}-\mathrm{T}_{2}\right)$ and the presence of metastases in regional lymph nodes $\left(\mathrm{N}_{1}\right)$. The data that we obtained for primary tumors were concordant with those for the five cell lines (Fig. 4).

\section{Discussion}

Previously, qPCR was not applied to study hTERT expression and copy number in SCC. The hTERT mRNA level was analyzed by RT-PCR at different stages of cervical squamous
Table II. Relative hTERT mRNAs level in SCC for two sets of primers and probes.

Relative hTERT mRNAs level (n-fold + range)

\begin{tabular}{|c|c|c|c|}
\hline $\begin{array}{l}\text { Sample } \\
\text { no. }\end{array}$ & $\begin{array}{c}\text { TNM } \\
\text { classification }\end{array}$ & Set 1 & Set 2 \\
\hline 1 & $\mathrm{~T}_{1 \mathrm{~b}} \mathrm{~N}_{0} \mathrm{M}_{0}$ & $10(9-11)$ & $9(6-13)$ \\
\hline 5 & $\mathrm{~T}_{1 \mathrm{~b}} \mathrm{~N}_{0} \mathrm{M}_{0}$ & $\leq 10$ & $10(7-12)$ \\
\hline 10 & $\mathrm{~T}_{1 \mathrm{~b}} \mathrm{~N}_{0} \mathrm{M}_{0}$ & No & No \\
\hline 13 & $\mathrm{~T}_{1 \mathrm{~b}} \mathrm{~N}_{0} \mathrm{M}_{0}$ & No & No \\
\hline 14 & $\mathrm{~T}_{1 \mathrm{~b}} \mathrm{~N}_{0} \mathrm{M}_{0}$ & $6.0(5-7)$ & $5(4-6)$ \\
\hline 15 & $\mathrm{~T}_{1 \mathrm{~b}} \mathrm{~N}_{0} \mathrm{M}_{0}$ & $14(12-16)$ & $10(8-12)$ \\
\hline 16 & $\mathrm{~T}_{1 \mathrm{~b}} \mathrm{~N}_{0} \mathrm{M}_{0}$ & $27(24-30)$ & $36(29-45)$ \\
\hline 17 & $\mathrm{~T}_{2 \mathrm{~b}} \mathrm{~N}_{0} \mathrm{M}_{0}$ & No & No \\
\hline 21 & $\mathrm{~T}_{2 \mathrm{a}} \mathrm{N}_{0} \mathrm{M}_{0}$ & $\leq 8$ & $5(4-6)$ \\
\hline 22 & $\mathrm{~T}_{2 \mathrm{~b}} \mathrm{~N}_{0} \mathrm{M}_{0}$ & $\leq 4$ & $3(2-5)$ \\
\hline 23 & $\mathrm{~T}_{2 \mathrm{a}} \mathrm{N}_{0} \mathrm{M}_{0}$ & $\leq 2$ & $2.1(1.7-2.6)$ \\
\hline 26 & $\mathrm{~T}_{2 \mathrm{a}} \mathrm{N}_{0} \mathrm{M}_{0}$ & $9(8-10)$ & $22(17-29)$ \\
\hline 27 & $\mathrm{~T}_{2 \mathrm{a}} \mathrm{N}_{0} \mathrm{M}_{0}$ & $7(6-8)$ & $9(7-11)$ \\
\hline 32 & $\mathrm{~T}_{2 \mathrm{a}} \mathrm{N}_{0} \mathrm{M}_{0}$ & $3(2-4)$ & $5.5(4-7)$ \\
\hline 37 & $\mathrm{~T}_{2 \mathrm{~b}} \mathrm{~N}_{1} \mathrm{M}_{0}$ & $\leq 4$ & $3(2-4)$ \\
\hline 38 & $\mathrm{~T}_{2 \mathrm{~b}} \mathrm{~N}_{1} \mathrm{M}_{0}$ & No & No \\
\hline 39 & $\mathrm{~T}_{2 \mathrm{~b}} \mathrm{~N}_{1} \mathrm{M}_{0}$ & $\leq 1.5$ & $2.5(2-3)$ \\
\hline 40 & $\mathrm{~T}_{2 \mathrm{~b}} \mathrm{~N}_{1} \mathrm{M}_{0}$ & $\leq 2$ & $1.0(0.8-1.3)$ \\
\hline 43 & $\mathrm{~T}_{2 \mathrm{~b}} \mathrm{~N}_{1} \mathrm{M}_{0}$ & No & $\leq 2$ \\
\hline 45 & $\mathrm{~T}_{2} \mathrm{~N}_{1} \mathrm{M}_{0}$ & $13(11-15)$ & $18(14-23)$ \\
\hline 46 & $\mathrm{~T}_{2 \mathrm{~b}} \mathrm{~N}_{1} \mathrm{M}_{0}$ & $91(86-95)$ & $80(72-95)$ \\
\hline
\end{tabular}

intraepithelium lesions. A significant increase in mRNA content was found in early and late dysplasias, 35-40\% and $89-96 \%$, respectively $(6,11)$. In our study, the increase of hTERT mRNA was found in $80 \%$ of all SCC samples and in $75 \%$ of cases at the initial stages of tumor development $\left(\mathrm{T}_{1} \mathrm{~N}_{0} \mathrm{M}_{0}\right)$. This increase was virtually independent from tumor size $\left(\mathrm{T}_{1}-\mathrm{T}_{2}\right)$ and from the presence of lymph node metastases. In this study, we also demonstrated that hTERT mRNA in SCC was synthesized in the form of functionally active full-length transcript. Increased level of full-size mRNA is in agreement with our previous data on detecting telomerase activity in SCC (6). Recently, increased $h T E R T$ protein expression (including early stages) was shown by immunohistochemical method (13). The absence of hTERT mRNA in $20 \%$ of cases in our experiments may be associated with possible switch to the alternative telomerase-independent mechanism of telomere elongation $(14,15)$, though this assumption requires experimental verification.

The mechanism of hTERT gene activation still remains unclear. Earlier, hTERT gene amplification in SCC was demonstrated by FISH in cell lines and in primary tumors $(4,5)$. In our study, qPCR data showed that hTERT was not amplified in all 33 SCC samples tested so far. It cannot be explained by inappropriate quality of DNA because in the 




Figure 3. The hTERT DNA gene copy number in primary SCC relative to the reference genes ACTB, GUSB and the two genes together.

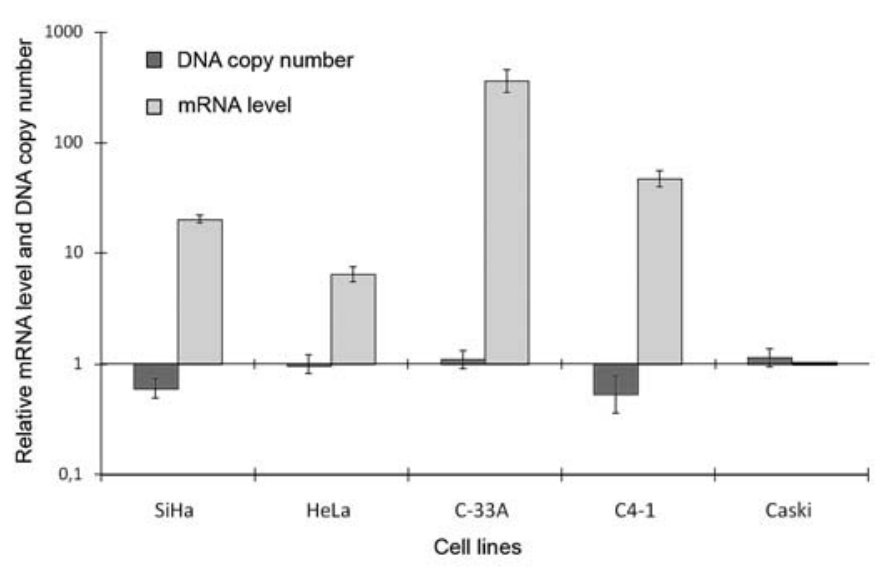

Figure 4. The quantitative evaluation of hTERT mRNA level and gene copy number in five cell lines. $h T E R T$ level is presented in comparison to CaSki cells, used as reference sample due to their minimal level of $h T E R T$ mRNA. same samples we found earlier that $C T D S P L / R B S P 3$ gene was deleted in 42\% (19/45) and amplified in 9\% (4/45) (8). Thus, hTERT transcription was activated in SCC independently of gene amplification. This effect could be caused by promoter demethylation and/or direct effect of HPV-encoded viral proteins. Methylation of the hTERT gene promoter was found in primary tumors and cell lines, but no correlation was found between methylation and hTERT mRNA level $(16,17)$. Possible role of proteins encoded by high risk HPV was studied and activation of hTERT transcription by HPV 16 E6 protein was demonstrated in human keratinocytes (18). In primary SCC, the positive correlation was found between viral load with oncogenic HPV and telomerase activity (19). Although hTERT amplification was detected in SCC $(4,5)$ and other cancers (20), several studies presented evidence of transcriptional $(16,17,21)$ and post-transcriptional (22) mechanisms of hTERT expression activation. These data agree with amplification-independent activation of $h T E R T$ 
expression observed in our study. Previously detected $h T E R T$ gene rearrangements could be a side effect of overall cancer genome instability, not related to activation of hTERT transcription.

\section{Acknowledgements}

We are grateful to Lev Kisselev for his remarks, discussion and editing of this manuscript. This study was supported by the Russian Ministry of Education and Science (State Contract no. 02.435.11.3016, lot 6), the Russian Foundation for Basic Research (project no. 05-04-49408 and 05-0448808) and the FIRCA Grant 0600-070-G223.

\section{References}

1. Autexier C and Lue NF: The Structure and function of telomerase reverse transcriptase. Annu Rev Biochem 75: 493-517, 2006.

2. Bettendorf O, Heine B, Kneif S, Eltze E, Semjonow A, Herbst H, Stein H, Bocker W and Poremba C: Expressionpatterns of the RNA component (hTR) and the catalytic subunit (hTERT) of human telomerase in non-neoplastic prostate tissue, prostatic intraepithelial neoplasia and prostate cancer. Prostate 55: 99-104, 2003

3. Horikawa I and Barrett JC: Transcriptional regulation of the telomerase hTERT gene as a target for cellular and viral oncogenic mechanisms. Carcinogenesis 24: 1167-1176, 2003.

4. Zhang A, Zheng C, Hou V, Lindvall C, Wallin K, Angstrom T, Yang X, Hellstrom A, Blennow E, Bjorkholm E, Zetterberg A, Gruber $\mathrm{A}$ and $\mathrm{Xu} \mathrm{D}$ : Amplification of the telomerase reverse transcriptase (hTERT) gene in cervical carcinomas. Genes Chromosomes Cancer 34: 269-275, 2002.

5. Zhang A, Zheng C, Lindvall C, Hou M, Ekedahl J, Lewensohn R, Yan Z, Yang X, Henrikson M, Blennow E, Nordenskjold V, Zetterberg A, Djorkholm M, Gruber A and Xu D: Frequent amplification of the telomerase reverse transcriptase gene in human tumors. Cancer Res 60: 6320-6325, 2000.

6. Oikonomou P, Mademitzis I, Messinis I and Tsezou A: Quantitative determination of human telomerase transcriptase messenger RNA expression in premalignant cervical lesions and correlation with human papillomavirus load. Human Pathol 7: 135-142, 2006.

7. Kisseljov FL, Kisseljova NP, Kobzeva VK, Gritsko TM, Semenova LA, Pavlova LS, Klaes R and von Knebel-Doeberitz M: State of human papilloma virus DNA in cervical carcinomas. Mol Biol 35: 399-404, 2001.

8. Anedchenko EA, Kisseljova NP, Dmitriev AA, Kisseljov FL, Zabarovsky ER and Senchenko VN: Tumor suppressor gene RBSP3 in cervical carcinoma: copy number and transcription level. Mol Biol 41: 77-85, 2007.

9. Manzeniuk OY, Malakho SG, Pekhov VM, Kosorukova IS and Poltaraus AB: Characterization of Russian universal kits for real-time PCR: application to molecular oncodiagnosis. Mol Biol 40: 305-311, 2006

10. Glantz SA: Primer of Biostatistics. 4th edition. McGraw-Hill Inc., NY, 1994.
11. Tsezou A, Oikonomou P, Kollia P, Mademtzis I, Kostopoulou E, Messinis I and Vamvakopoulos N: The role of human telomerase catalytic subunit transcription in cervical dysplasias. Exp Biol Med 230: 263-270, 2005.

12. Skvortsov DA, Gasparian NM, Rubtsova MP, Zvereva ME, Fedorova MD, Pavlova LS, Bogdanov AA, Dontsova OA and Kisseljov FL: Telomerase as a potential marker for early diagnosing cervical carcinoma. Dokl Biochem Biophys 408: 158-160, 2006.

13. Branca M, Giorgi C, Ciotti M, Santini D, Di Bonito L, Costa S, Benedetto A, Bonifacio D, Di Bonito P, Paba P, Accardi L, Mariani L, Ruutu M, Syrjanen S, Favalli C and Syrjanen K: Upregulation of telomerase (hTERT) is related to the grade of cervical intraepithelial neoplasia, but is not an independent predictor of high-risk human papillomavirus, virus persistence, or disease outcome in cervical cancer. Diagn Cytopathol 34: 739-748, 2006.

14. Atkinson SP, Hoare SF, Glasspool RM and Keith WN: Lack of telomerase gene expression in alternative lengthening of telomere cells is associated with chromatin remodeling of the hTR and hTERT gene promoters. Cancer Res 65: 7585-7590, 2005.

15. Jiang WQ, Zhong ZH, Henson JD and Reddel RR: Identification of candidate alternative lengthening of telomeres genes by methionine restriction and RNA interference. Oncogene 26: 4635-4647, 2007.

16. Widschwendter A, Muller HM, Hubalek MM, Wiedemair A, Fiegl H, Goebel G, Mueller-Holzner E, Marth C and Widschwendter M: Methylation status and expression of human telomerase reverse transcriptase in ovarian and cervical cancer. Gynecol Oncol 93: 407-416, 2004.

17. Zinn RL, Pruitt K, Eguchi S, Baylin SB and Herman JG: hTERT is expressed in cancer cell lines despite promoter DNA methylation by preservation of unmethylated DNA and active chromatin around the transcription start site. Cancer Res 67: 194-201, 2007.

18. Baege AC, Berger A, Schlegel R, Veldman T and Schlegel R: Cervical epithelial cells transduced with the papillomavirus E6/ E7 oncogenes maintain stable levels of oncoprotein expression but exhibit progressive, major increases in hTERT gene expression and telomerase activity. Am J Pathol 160: 1251-1257, 2002.

19. Kailash U, Soundararajan CC, Lakshmy R, Arora R, Vivekanandhan S and Das BC: Telomerase activity as an adjunct to high-risk human papillomavirus types 16 and 18 and cytology screening in cervical cancer. Br J Cancer 95: 1250-1257, 2006

20. Fan X, Wang Y, Kratz J, Barat D, Robitaille Y, Moghrabi A, Perlman E, Dang C, Burger P and Eberhart C: hTERT gene amplification and increased transcription in central nervous system embryonal tumors. Am J Pathol 162: 1763-1769, 2003.

21. Racek T, Mise N, Li Z, Stoll A and Putzer BM: C-terminal p73 isoforms repress transcriptional activity of the human telomerase reverse transcriptase (hTERT) promoter. J Biol Chem 280: 40402-40405, 2005.

22. Ulaner GA, Hu JF, Vu TH, Oruganti H, Giudice LC and Hoffman AR: Regulation of telomerase by alternate splicing of human telomerase reverse transcriptase (hTERT) in normal and neoplastic ovary, endometrium and myometrium. Int $\mathbf{J}$ Cancer 85: 330-335, 2000. 